\title{
Answer to medical quiz: image
}

1. Tubercular spondylodiscitis of C4-C5 with prevertebral collection and paravertebral abscesses.

Retropulsion of C4-C5 vertebra causes spinal cord compression with myelomalacic changes.

Bilateral pulmonary tuberculosis with cavitations.

2. Pott's disease

3. a. Patients with spinal disease and advanced neurological deficits

b. Patients with spinal disease and worsening neurological deficits progressing while on appropriate therapy

c.Patients with spinal disease and kyphosis $>40$ degrees at the time of presentation

4. The response to therapy may be monitored by clinical indicators such as pain, constitutional symptoms, mobility, and neurologic findings. The role of inflammatory markers in monitoring the response to TB therapy is limited. It is not useful to perform serial radiographs since radiographic findings may appear to progress during appropriate treatment.

\section{Role of MRI in the diagnosis of Pott's disease}

Magnetic resonance imaging (MRI) is a standard radiological invetigation for evaluating disk-space infection and osteomyelitis of the spine and is most effective for demonstrating the extension of disease into soft tissues and the spread of tuberculous debris under the anterior and posterior longitudinal ligaments. ${ }^{1}$

Contrast-enhanced MRI findings are useful in differentiating tuberculous spondylitis from pyogenic spondylitis. MRI findings in Pott disease include thin and smooth enhancement of the abscess wall and a well-defined paraspinal abnormal signal. Thick and irregular enhancement of the abscess wall and an illdefined paraspinal abnormal signal suggest pyogenic spondylitis. $^{2}$

Involvement of the disk is typically a characteristic of infectious spondylitis; however, and Pott disease can present with atypical features resembling neoplastic lesions.

Findings of an intradural extramedullary mass at the lower end of the spinal cord associated with holocord T2 hyperintensities of the choroid has been described in intramedullary tubercular abscesses "precipitation sign." ${ }^{3}$ Three MRI parameters have been found to be strongly suggestive of spinal tuberculosis: subligamentous spread of abscess, vertebral body collapse, and large abscess collection with thin abscess wall. ${ }^{4}$

\section{REFERENCES}

1. Ansari S, Amanullah MF, Ahmad K, Rauniyar RK. Pott's Spine: Diagnostic Imaging Modalities and Technology Advancements. N Am J Med Sci 2013 Jul; 5(7):404-11.

2. Jung NY, Jee WH, Ha KY, Park CK, Byun JY. Discrimination of tuberculous spondylitis from pyogenic spondylitis on MRI. AJR Am J Roentgenol 2004 Jun; 182(6):1405-10

3. Sivalingam J, Kumar A. Spinal Tuberculosis Resembling Neoplastic Lesions on MRI. J Clin Diagn Res 2015 Nov; 9(11):TC01-3.

4. Kanna RM, Babu N, Kannan M, Shetty AP, Rajasekaran $\mathrm{S}$. Diagnostic accuracy of whole spine magnetic resonance imaging in spinal tuberculosis validated through tissue studies. Eur Spine J 2019 Dec; 28(12):3003-10. 